\title{
APLIKASI PENGOLAHAN DATA BARANG PADA TOKO FAMILY COMPUTER CINERE DEPOK BERBASIS JAVA
}

\author{
Farhan Jazmi $^{1}$, Sri Melati Sagita ${ }^{2}$, Nurfidah Dwitiyanti ${ }^{3}$ \\ Program Studi Teknik Informatika, Fakultas Teknik dan Ilmu Komputer, \\ Universitas Indraprasta PGRI \\ Jalan Raya Tengah No 80, Kelurahan Gedong, Pasar Rebo, Jakarta Timur \\ Farhanjazmi81@gmail.com¹, 61tamelati2013@gmail.com², nurfidah.pulungan@gmail.com ${ }^{3}$
}

\begin{abstract}
Abstrak
Pada era teknologi dan informasi, sebuah teknologi yang handal dapat berperan penting dalam kemajuan bisnis suatu perusahaan. Toko Family Computer merupakan salah satu perusahaan yang menawarkan jasa dan barang untuk keperluan komputer. Namun, perusahaan ini hingga saat ini masih menggunakan sistem manual dalam pengolahan datanya, sehingga sering kali membuat pihak perusahaan kesulitan dalam mencari dan mengontrol barang-barang yang ada di gudang Hal ini juga mengakibatkan kerugian yang tidak terhitung dan tidak terduga bagi perusahaan. Berdasarkan permasalahan tersebut, maka perlu dirancang sebuah sistem informasi yang sesuai dan dibutuhkan oleh perusahaan. Tujuan dari penelitian ini adalah menganalisa sistem yang sedang berjalan pada toko Family Computer dan merancang sistem informasi bagi perusahaan. Pada penelitian ini, metode yang digunakan adalah metode Research and Development dan sistem waterfall untuk sistem pengembangannya. Sedangkan dalam pengumpulan data penelitian, dilakukan observasi langsung ke toko, wawancara kepada pihak terkait ditoko dan kajian literatur. Hasil dari penelitian ini diperoleh bahwa dengan diterapkanya aplikasi sistem informasi ini, pengolahan data barang pada toko Family Computer menjadi lebih baik dan lebih terstruktur.
\end{abstract}

Kata Kunci: Aplikasi Pengelolaan Data Barang, Java, Metode Research and Development.

\section{Abstract}

In the era of technology and information, a reliable technology can play an important role in the business progress of a company. Family Computer Store is one of the companies that offer services and goods for computer purposes. However, this company is still using manual systems in its data processing, so it often makes it difficult for the company to find and control the goods in the warehouse. Based on these problems, it is necessary to design an information system that is appropriate and needed by the company. The purpose of the study was to analyze the systems running in the Family Computer store and design information systems for companies. In this study, the methods used are research and development methods and waterfall systems for their development systems. While in the collection of research data, direct observation to the store, interviews to related parties in the store and literature studies. The results of this study obtained that with the application of this information system, the processing of goods data in family computer stores becomes better and more structured.

Keywords: Goods Data Management Application, Java, Research and Development Method.

\section{PENDAHULUAN}

Pada era teknologi dan informasi, sebuah teknologi yang handal dapat memiliki peranan penting untuk kemajuan sebuah bisnis. Teknologi yang memberikan informasi secara akurat dan tepat pun dapat menjadi sarana yang dapat meminimalisir waktu dan biaya sebagaimana lazimnya yang patut dilakukan oleh para pelaku bisnis (Sutabri 2012). Toko Family Computer adalah salah satu perusahaan yang menawarkan jasa dan barang untuk keperluan komputer. Namun, perusahaan ini hingga saat ini belum memiliki teknologi yang sekiranya diperlukan untuk membantu mengontrol data-data harian. Hal inilah yang kerap kali membuat perusahaan kehilangan banyak data atas penjualan ataupun barang-barang yang berada pada stok gudang. Masih digunakanya sistem manual membuat data-data tercecer, hilang, dan tidak dapat dicari lagi. Kerap kali pihak perusahaan kebingungan dalam mencari dan mengontrol barang-barang yang ada di gudang sehingga barang tersebut dinyatakan hilang tanpa adanya bukti.(Prasetyo 2015). Tidak terintegrasinya sistem pencatatan manual dengan menggunakan banyak buku besar mengakibatkan kerugian yang tidak terhitung dan tidak terduga (Veza 2017). Terutama data penjualan, kontrol 
barang, pembukuan, dan data stok barang yang ada. Melihat permasalahan tersebut maka dirancanglah sebuah sistem informasi persediaan barang. Dengan adanya sistem informasi tersebut diharapkan tidak terjadi lagi kesalahan dalam penghitungan data, pencarian atau penelusuran data pesediaan barang agar menjadi lebih mudah dan cepat (Mauluddin dan Santini 2017). Oleh, karena itu, salah satu cara untuk mempermudah kegiatan pencatatan adalah dengan menggunakan sebuah aplikasi/sistem. Berdasarkan uraian diatas maka peneliti tertarik untuk melakukan penelitian yang berjudul "Aplikasi Pengolahan Data Barang pada Toko Family Computer Cinere Depok Berbasis Java NetBeans".

\section{PENELITIAN RELEVAN}

Beberapa penelitian relevan yang digunakan sebagai acuan pada penelitian ini adalah sebagai berikut:

Penelitian oleh (Dimas 2018), dengan judul Perancangan dan Penerapan Sistem Inventory Barang pada Toko BIG Store Padang Dengan Menggunakan Bahasa Pemrograman Java dan MySQL. Tujuan penelitian ini untuk membantu membuat aplikasi dan mengelola data persediaan barang, yang bertujuan untuk meningkatkan kegiatan operasional toko dan Memudahkan pemilik dalam meminimumkan biaya persediaan barang.

Penelitian selanjutnya, oleh (Fitriani 2017) dengan judul Aplikasi Pengelolaan Transaksi Barang di Toko Material Heri Berbasis Desktop. Tujuan penelitian ini untuk membantu dalam penyimpanan data didalam database, agar data menjadi lebih aman dan pengelolaan data dapat dilakukan dengan lebih cepat.

Persamaan dari penelitian sebelumnya dengan penelitian ini adalah sama-sama berbasis java dan untuk mempermudah pengolahan data. Perbedaan dari penelitian sebelumnya dengan penelitian ini adalah pada proses transaksi.

\section{METODE PENELITIAN}

Metode penelitian yang digunakan peneliti adalah metode Research and Development dan sistem waterfall untuk sistem pengembangannya. Menurut (Sugiyono 2016), "Metode penelitian dan pengembangan atau dalam bahasa inggrisnya Research and Development adalah metode penelitian yang digunakan untuk menghasilkan produk tertentu, dan menguji keefektifan prosuk tersebut".

Metode yang digunakan untuk pengumpulan data serta pengambilan keterangan yang dibutuhkan untuk merancang program dalam penelitian ini dilakukan dengan cara :

1. Observasi (pengamatan)

Merupakan metode yang dilakukan oleh penulis secara langsung ke lapangan untuk memperoleh sumber data yang sesuai dengan kebutuhan yang diperlukan(Yulianti dan Yupianti 2012). Penulis terjun langsung ke lapangan untuk melakukan pengamatan dan meneliti secara langsung data-data yang berkaitan dengan bahan laporan secara cermat dan sistematik. Penelitian dilakukan pada bulan Juni 2020 di Toko Family Computer.

2. Wawancara

Dalam melakukan wawancara ini,peneliti melakukan Tanya jawab kepada pihak yang terkai(Rosaliza 2015), yaitu kepada pemilik Toko Family Computer dengan mengajukan beberapa pertanyaan yang ada kaitannya dengan kebutuhan data yang dikumpulkan peneliti.

3. Dokumentasi

Penulis melakukan pengumpulana data dengan cara mencatat semua data yang ada pada dokumen atau arsip di bagian pendataan(Guba dan Lincoln 2014), pada Toko Family Computer.

\section{HASIL DAN PEMBAHASAN}

\section{Analisis Permasalahan}

Berdasarkan analisis proses yang dilakukan oleh penulis pada toko family computer terdapat beberapa permasalahan sebagai berikut :

1. Sistem masukan data yang masih menggunakan sistem sederhana atau manual, kurang sistematis, efektif dan efisien.

2. Sulitnya melakukan pencarian data barang karena harus mencari satu persatu daftar barang dalam buku besar. 
3. Kesalahan dalam perhitungan yang membuat kurang efektifnya dalam proses pengolahan data.

4. Data laporan dari segi informasi yang disajikan kurang lengkap.

\section{Alternatif Penyelesaian Masalah}

Penyelesaian masalah yang diharapkan pada toko family computer lebih mendasar dan terletak pada sistem yang dijalankan di toko, sehingga perlu adanya penyelesaian masalah yang tepat, serta mengambil langkah-langkah sesuai dengan yang diharapkan pemimpin toko agar kedepanya toko family computer semakin maju. Adapun penyelesaian masalah tersebut adalah :

1. Merancang system aplikasi pengolahan data barang yang dapat dilakukan dengan cepat dan akurat.

2. Membuat database yang sistematis sehingga memudahkan dalam pencarian data yang dibutuhkan dalam pembuatan laporan.

3. Membuat aplikasi dengan semaksimal mungkin untuk mengurangi kesalahan atau kehilangan data.

4. Membuat aplikasi yang dapat menampilkan informasi secara lengkap menggunakan bahasi pemograman Java.

Dengan perancangan sistem informasi aplikasi pengolahan data ini diharapkan dapat mempermudah dalam proses laporan setiap bulanya, dan sebagai informasi yang dapat dijadikan bahan pertimbangan guna menunjang pengambilan keputusan untuk tujuan yang lebih baik.

\section{Diagram Konteks Sistem yang Diusulkan}

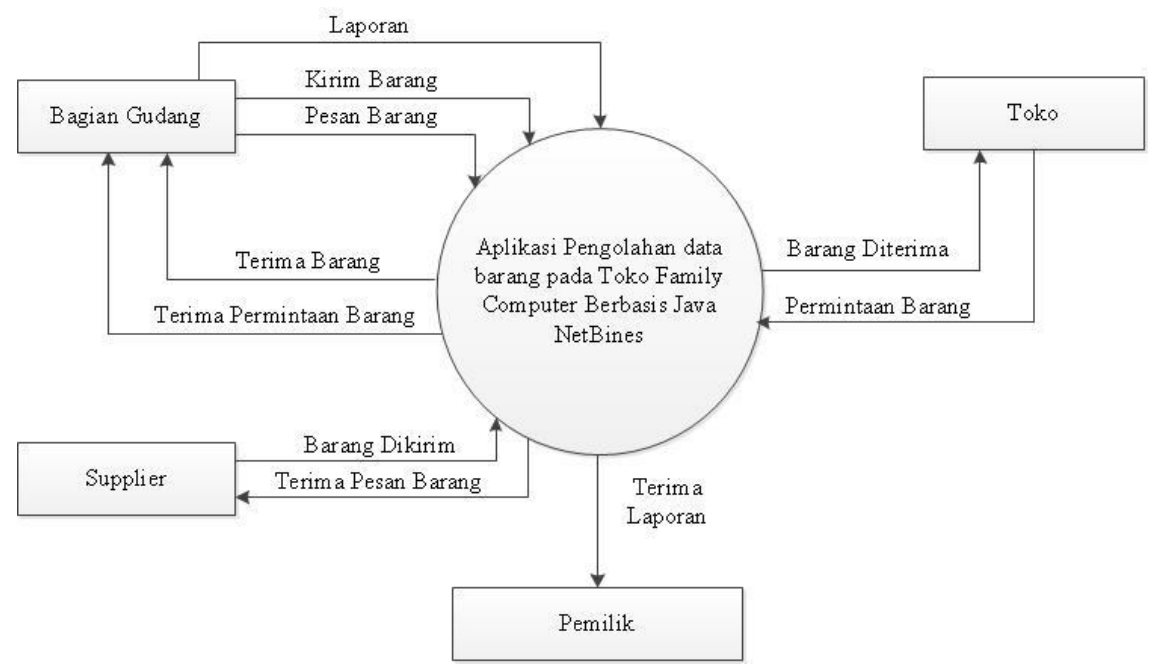

Gambar 1. Diagram Konteks.

Gambar diatas merupakan diagram konteks yang menunjukan setiap proses dari awal pemesanan barang pada supplier sampai proses penyiapan barang pada bagian gudang dan komponen seluruh sistem yang ada pada aplikasi pengolahan data barang pada toko Family Computer berbasis java netbeans. 


\section{Entity Relationship Diagram (ERD)}

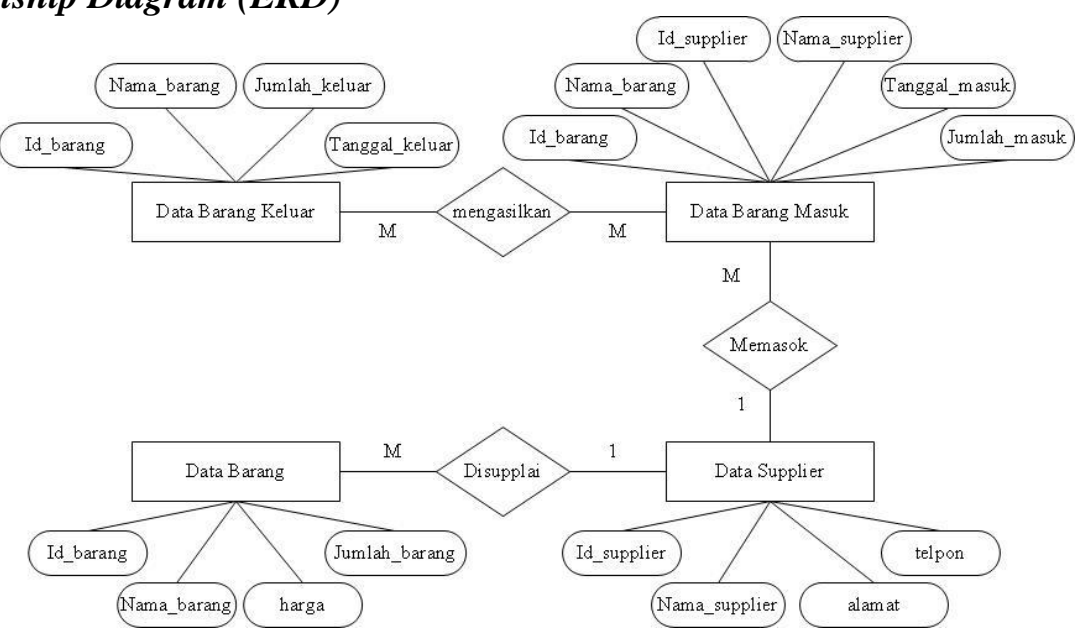

Gambar 2.Entity Relationship Diagram (ERD)

Gambar diatas merupakan bentuk dari entity relationship diagram dari sebuah alur data yang akan mengalir dari satu proses ke proses berikut nya hingga menjadi sebuah data yang dapat digunakan untuk laporan persediaan barang yang dibutuhkan oleh toko Family Computer.

\section{Tampilan Layar}

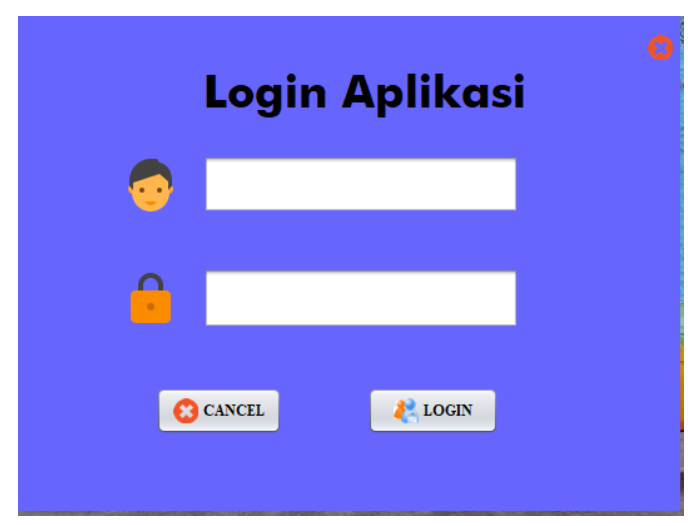

Gambar 3.login

Layar diatas menampilkan from login, sehingga masukan user dan password yang sudah dibuat dan klik login untuk menampilkan menu utama.

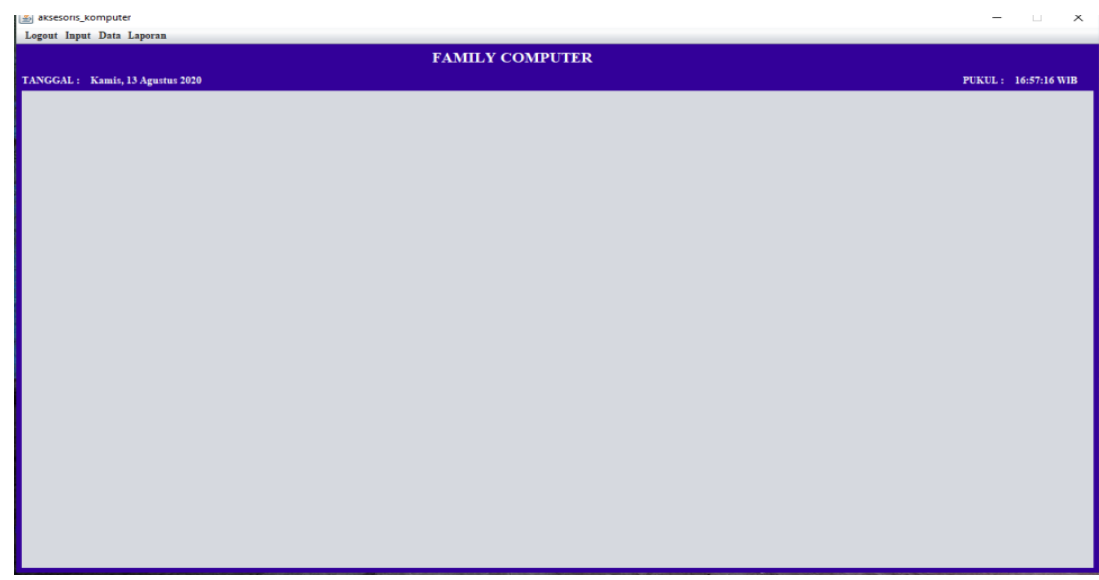

Gambar 3. Menu Utama 
Pada tampilan menu utama terdapat Menu Bar yang di dalamnya terdapat beberapa Menu Item yaitu: Menu Input, Menu Data, Menu Laporan.

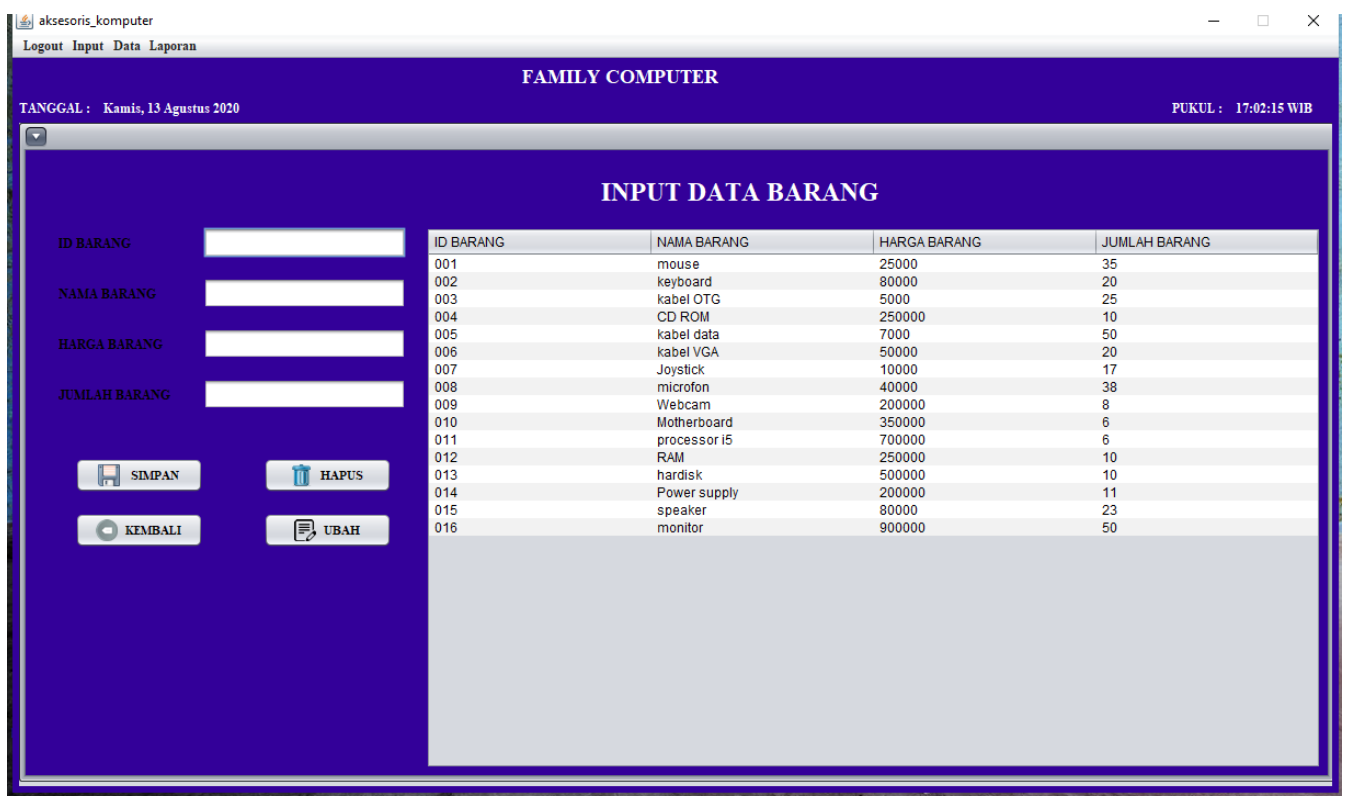

Gambar 4. Input Data Barang

Tampilan form input data barang adalah tampilan yang akan muncul ketika admin memilih menu bar input dan memilih menu item input data barang. Form input data barang ini digunakan untuk memasukan data barang yang akan menjadi detail pada barang yang masuk dan juga barang yang keluar.

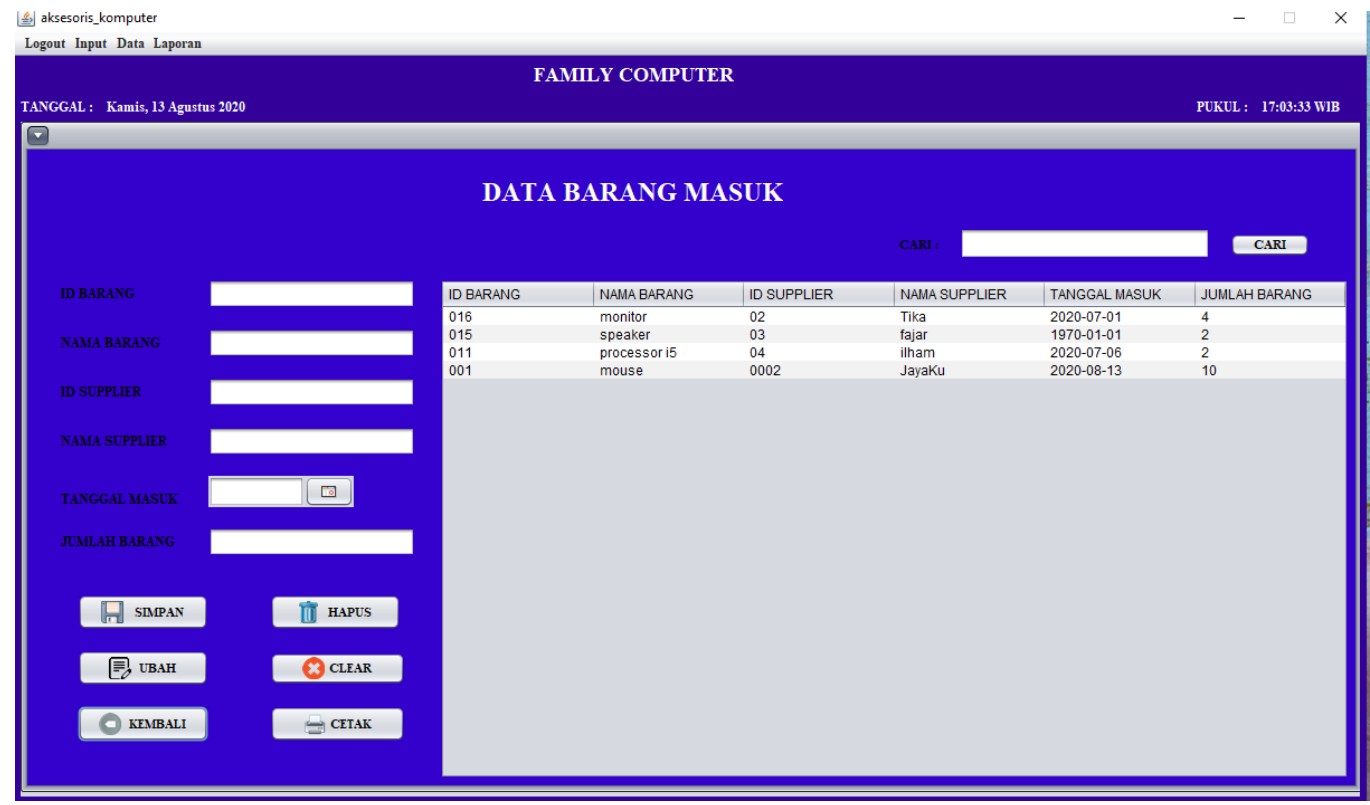

Gambar 5. Data Barang Masuk

Tampilan form data barang masuk adalah tampilan yang akan muncul ketika admin memilih menu bar data dan memilih menu item barang masuk. Form data barang masuk ini digunakan untuk memasukan data barang masuk yang akan disimpan ke dalam database. 


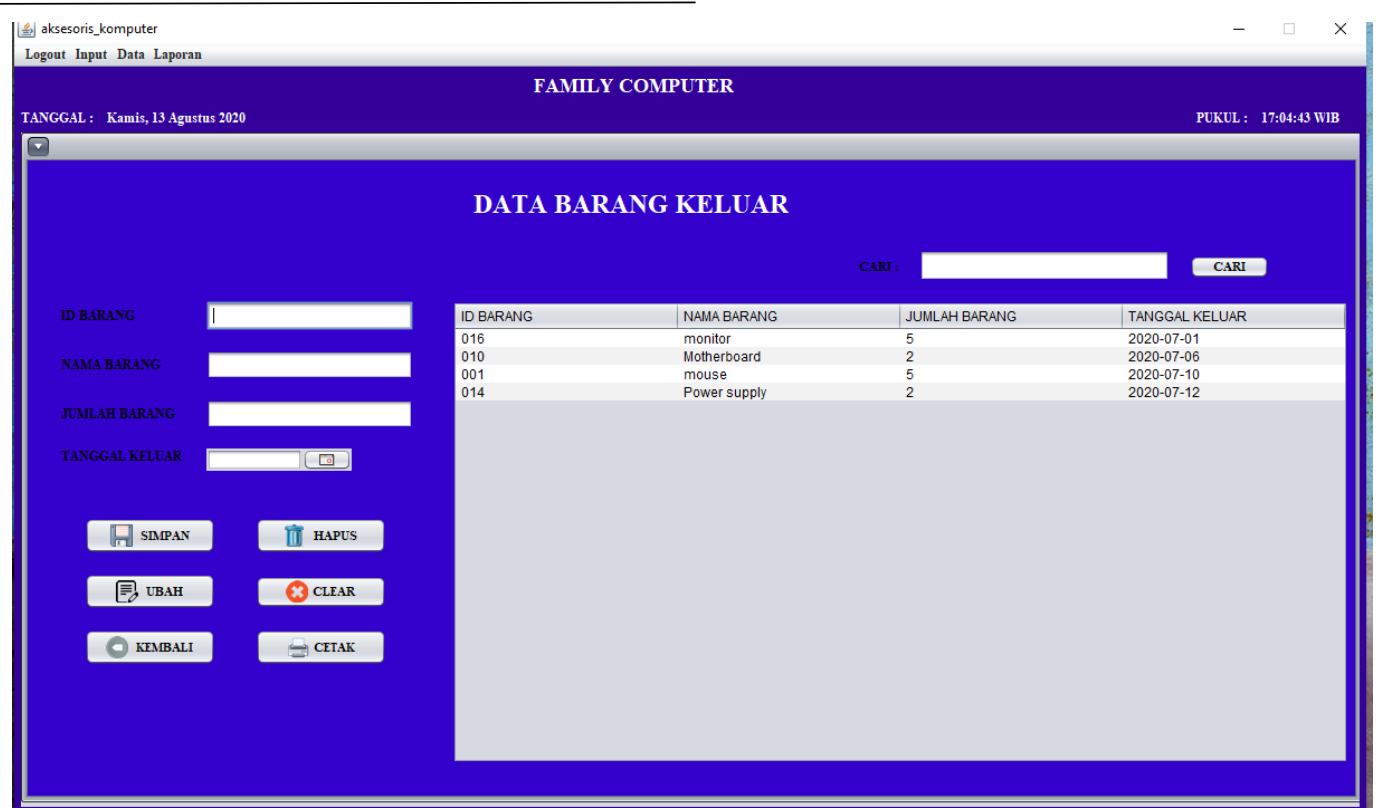

Gambar 6. Data Barang Keluar

Tampilan form data barang keluar adalah tampilan yang akan muncul ketika admin memilih menu bar data dan memilih menu item barang keluar. Form data barang keluar ini digunakan untuk memasukan data barang keluar yang akan disimpan ke dalam database.

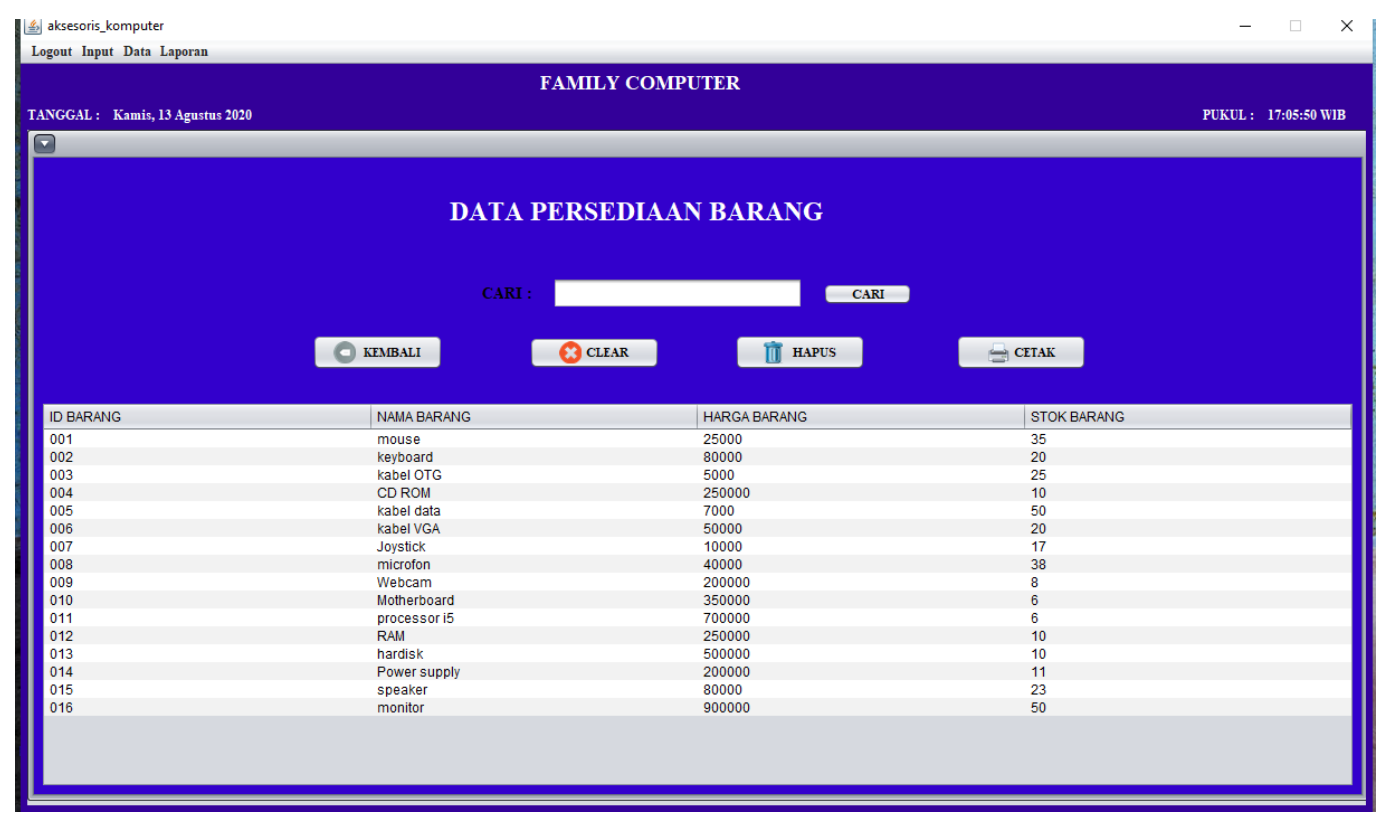

Gambar 7. Persediaan Barang

Tampilan form data persediaan barang adalah tampilan yang akan muncul ketika admin memilih menu bar data dan memilih menu item persediaan barang. form data persediaan barang ini di dalamnya terdapat informasi mengenai data persediaan barang yang di ambil berdasarkan data barang yang masuk dan data barang yang keluar. Menu persediaan ini juga digunakan untuk akses mencetak laporan persediaan barang. 


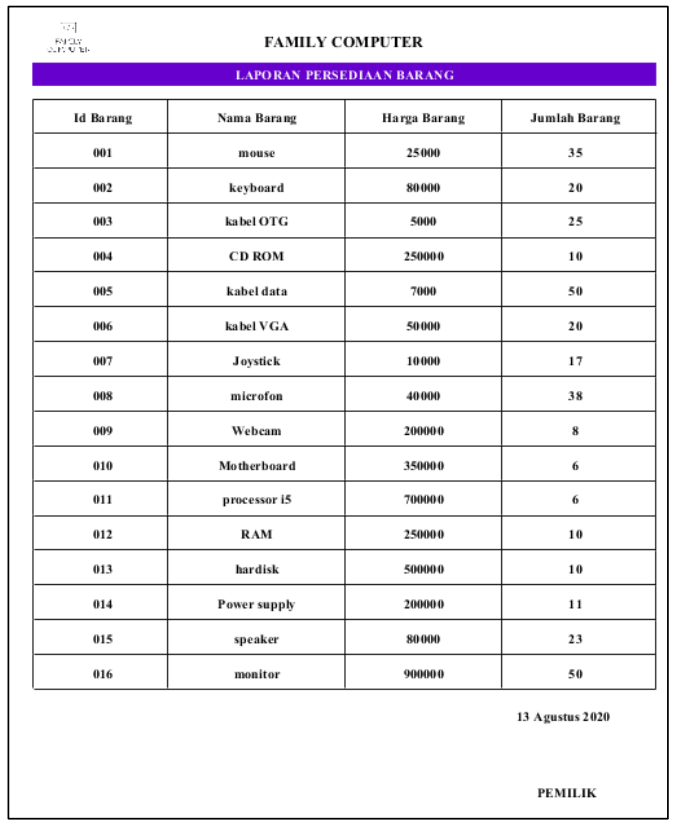

Gambar 8. Laporan Persediaan Barang

Tampilan laporan persediaan barang berisikan data barang beserta stok akhirnya yang telah di masukkan sebelumnya ke dalam database. Selanjutnya laporan persediaan tersebut dicetak dan diberikan kepada pemilik Toko Family Computer.

\section{SIMPULAN}

Berdasarkan hasil dari pembahasan yang telah diuraikan pada bab - bab sebelumnya dan menyesuaikan diri rumusan masalah yang ada, maka kesimpulan yang diperoleh penulis yaitu. Sistem penjualan yang berjalan diketahui oleh penulis melalui wawancara dan observasi langsung masih menggunakan sistem manual. Pemilik toko masih mencatat penjualan melalui buku besar.

1. Perancangaan aplikasi pengolahan data barang pada Toko Family Computer menggunakan Bahasa pemograman Java agar dapat mempermudah dalam mengelola data barang.

2. Pengujian aplikasi pengolahan data barang dilakukan dengan menyimpan seluruh data barang didalam database agar mempermudah dalam melakukan pencetakan laporan.

3. Aplikasi pengolahan data barang diimplementasikan oleh bagian gudang toko family computer untuk mempermudah dalam mengolah data barang.

\section{DAFTAR PUSTAKA}

Dimas. 2018. "Perancangan dan Penerapan Sistem Inventory Barang Pada Toko BIG Store Padang Dengan Menggunakan Bahasa Pemrograman Java dan MySQL" 3 (2): 54-67.

Fitriani. 2017. "Aplikasi Pengelolaan Transaksi Barang Di Toko Material Heri Berbasis Desktop" 9 (2): 84-89.

Guba dan Lincoln. 2014. "Memahami Studi Dokumen Dalam Penelitian Kualitatif.” Wacana 13 (2): 177-81.

Mauluddin, Syahrul, dan Nakya Santini. 2017. "Sistem Informasi Persediaan Dan Penjualan Barang Berbasis Desktop Di D-Net House.” Prosiding Saintiks FTIK UNIKOM, 1-6. http://prosiding-saintiks.ftik.unikom.ac.id/jurnal/sisteminformasi-persediaan.32.

Prasetyo, Dwi. 2015. "Pembuatan Aplikasi Pengolahan Data Transaksi dan Penjualan Pendahuluan Pembahasan" 16 (1): 30-33.

Rosaliza, Mita. 2015. “1099-Article Text-1955-1-10-20180418.pdf.” Jurnal Ilmu Budaya.

Sugiyono. 2016. "Metode Penelitian dan Pengembangan (Research and Development/R\&D)." Bandung: Alfabeta, 334.

Sutabri, Tata. 2012. "Konsep Sistem Informasi.” Jurnal Administrasi Pendidikan UPI 3 (1): 248.

Veza, Okta. 2017. "Perancangan Sistem Informasi Inventory Data Barang pada PT.Andalas Berlian Motors (Studi Kasus: PT Andalas Berlian Motors Bukit Tinggi)." Jurnal Teknik Ibnu Sina (JT-IBSI) 2 (2): 121-34. https://doi.org/10.36352/jt-ibsi.v2i2.63.

Yulianti, Liza, dan Yupianti. 2012. "Sistem Informasi Persediaan Barang Pada Pt. Surya Nusa Bhaktindo Bengkulu." Akuntansi 8 (1): 28. 